\title{
Role of Voltage and Gas Pressure in Determining the Mean Diameter of Sn-Bi-Ag Intermetallic Compound Nanoparticles Formed by Pulsed Wire Discharge
}

\author{
Dae Geol Jeong', Jae Min Cha', Dae Sung Kim¹, Ju Hyeong Kim', Hwa Jin Jeong ${ }^{1}$, \\ Jae Young Shin ${ }^{1}$, Jun Hyeon Bae ${ }^{1}$, Bong Ki Ryu ${ }^{1, *}$, Hisayuki Suematsu', and Kenta Tanaka ${ }^{2}$ \\ ${ }^{1}$ Department of Materials Science and Engineering, Pusan National University, Pusan 46241, Republic of Korea \\ ${ }^{2}$ Extreme Energy-Density Research Institute, Nagaoka University of Technology, Niigata 940-2188, Japan
}

\begin{abstract}
Nanoscale Sn-Bi-Ag compound powders were successfully synthesized using the pulsed wire discharge (PWD) method. In PWD, when a high current is passed through high-density metal wires, the wires explode because of resistance heating, forming fine particles or metal vapor. In this study, we used $\mathrm{Sn}-\mathrm{Bi}$ and $\mathrm{Ag}$ wires in order to obtain three-component nanopowders. A high current was applied to the wires between the electrodes in a $\mathrm{N}_{2}$ atmosphere. We discussed the results based on the $\mathrm{K}$ factor, which is the ratio of the charging energy of the capacitor to the vaporization energy of the wire. The three-component (Sn-Bi-Ag) nanoparticles were synthesized under a $\mathrm{N}_{2}$ atmosphere at 4 and $6 \mathrm{kV}$. From the particle-size distribution curves, it was found that the mean particle diameter $\left(\mathrm{D}_{1}\right)$ values of the $\mathrm{Sn}-\mathrm{Bi}$ and $\mathrm{Ag}$ nanopowders were within the range of $16.32-42.37 \mathrm{~nm}$ under each condition. The melting point of the $\mathrm{Sn}-\mathrm{Bi}-\mathrm{Ag}$ nanoparticles was found to be within the range of $188.68-214.97{ }^{\circ} \mathrm{C}$, which is about $40{ }^{\circ} \mathrm{C}$ lower than that obtained from the phase diagram and computational thermodynamics of the Sn-Bi-Ag system. In this study, the nanopowders were obtained by subjecting the wires at extreme energies, to improve their solid solubility.
\end{abstract}

(Received February 8, 2017; Accepted July 26, 2017)

Keywords: alloy wire, nanoparticles, pulsed wire discharge, three-component

\section{INTRODUCTION}

Sn-Bi-Ag compounds have become more popular as lead-free solder materials than $\mathrm{Sn}-3.5 \mathrm{Ag}$ compounds because they have a lower melting point, high strength, and good wettability [1-4]. However, their performance is not comparable to $\mathrm{Sn}-37 \mathrm{~Pb}$ materials. In order to improve the performance of $\mathrm{Sn}-\mathrm{Bi}-\mathrm{Ag}$ based lead-free solder materials, various methods, such as the addition of indium $[5,6]$ and nano-additives [7], have been used. The addition of indium improves the wettability and decreases the melting point. However, it also reduces mechanical strength. The addition of nano-additives prevents $\mathrm{Ag}_{3} \mathrm{Sn}$ coarsening and decreases the melting point. However, the addition of nano-additives results in binding and distribution because of the size difference between the micro-solder and nano-additive particles. One

* Corresponding Author: Bong Ki Ryu [Tel: +82-51-510-2384, E-mail: bkryu@pusan.ac.kr]

Copyright (c) The Korean Institute of Metals and Materials possible way to overcome these problems is to make nano-sized lead-free solder materials. According to the Lindemann theory, at nanoscale, the melting point of materials decreases because of an increase in the average atomic distance. This decrease in the melting point improves the wettability of nano-sized solder materials [8-17]. In nano-sized solder materials, the reaction interface is stabilized, which also suppresses the growth of intermetallic compounds [18].

Wire explosion is a technique for synthesizing nanoparticles [19-22]. When a high current is passed through high-density metal wires, the wires explode because of resistive heating, thus forming fine particles or metal vapor. With this technique, it is possible to reach very high temperatures of 104-106 K within a short duration of 1-50 $\mu \mathrm{s}$ at a lower cost compared to other techniques, by controlling the amount of energy supplied to the wires. An additional advantage of this technique is that it enables the adjustment of 


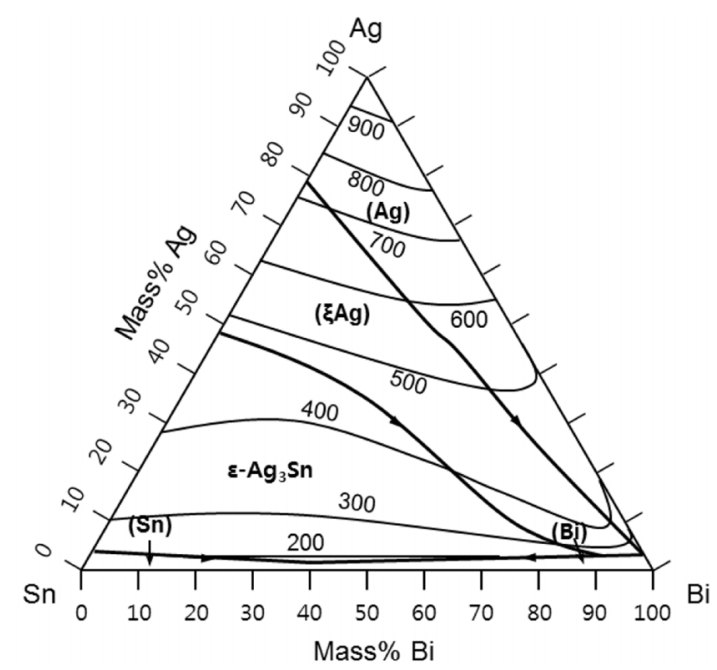

Fig. 1. Ag-Sn-Bi ternary phase diagram.

the average particle size. Moreover, by adjusting the atmosphere around the metal wires and by using a variety of raw materials ranging from metal powders $[23,24]$ to oxides [25], nitrides [26], and carbide powders [27], it is possible to produce alloy powders, chemical compounds, or composite material powders.

However, intermetallic Sn-Bi-Ag compounds are not ductile enough to form thin wires (less than $0.3 \mathrm{~mm}$ in diameter). Since most alloy metals are brittle, reports on the pulsed wire discharge (PWD) of alloy wires for the fabrication of alloy nanopowders are limited. In order to synthesize alloy nanopowders, PWD has been performed using two types of wires [28,29]. For this reason, research has been focused on reducing the diameter of $\mathrm{Sn}-\mathrm{Bi}$ or $\mathrm{Sn}$ and $\mathrm{Bi}$ wires for use in the PWD method. There are only a few studies on two-component nanopowders and even fewer studies on three-component nanopowders. Recently, we reported the synthesis of nanopowders using $\mathrm{Sn}-\mathrm{Bi}$ alloy wires [30]. Motivated by our previous study [30], we herein, report the synthesis of three-component nanopowders. In the present study, two types of wires (Sn-58Bi and $\mathrm{Ag}$ wires) were used for the fabrication of the three-component nanopowders by PWD. We found that setting up the wires was very important for the fabrication. Hence, to synthesize homogeneous nanopowders, we placed two lines in parallel.

In this study, we conducted experiments using $\mathrm{Sn}-58 \mathrm{Bi}$

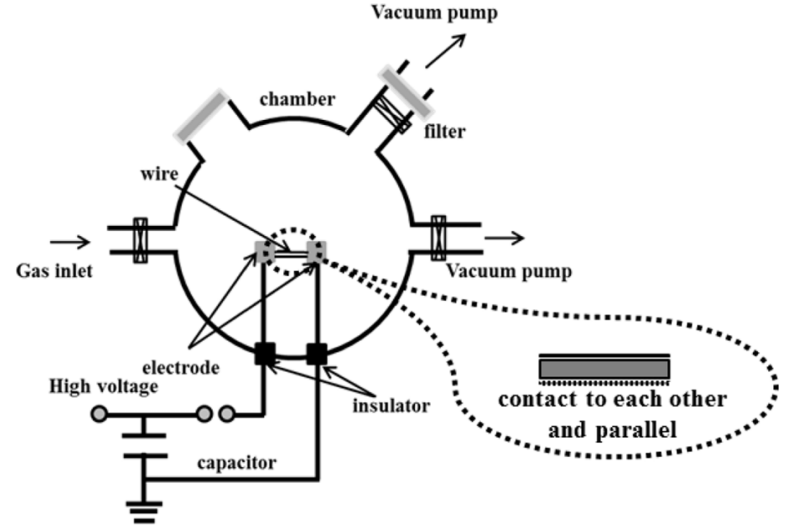

Fig. 2. Experimental setup for the PWD method.

wire and Ag wire because Ag-Sn-Bi has the lowest melting point in the Sn-58Bi composition (Fig. 1). We synthesized three-component nanopowders by subjecting the wires to extreme energies using the PWD method to overcome their limited solid solubility. And, we focused on determining the conditions necessary to reduce the size of the nanopowders, which is an important factor to lower their melting point, by adjusting the voltage and pressure, which can be used as variables in the PWD device.

\section{EXPERIMENTAL PROCEDURE}

Figure 2 shows the experimental setup for the PWD method. In order to carry out the PWD method, Sn-58Bi and $\mathrm{Ag}$ wires were prepared. The diameter and length of the $\mathrm{Sn}-58 \mathrm{Bi}$ wires were 0.5 and $32 \mathrm{~mm}$, respectively, while the Ag wires were $0.1 \mathrm{~mm}$ in diameter and $32 \mathrm{~mm}$ in length. The wires were placed on electrodes in a chamber. A filter paper was placed on the detecting valve and pump. The chamber was evacuated to less than $50 \mathrm{~Pa}$ using a pump and then filled with $\mathrm{N}_{2}$ gas at 50 and $100 \mathrm{kPa}$. Then, a capacitor was charged using a high-voltage DC power supply. The capacitor had a capacitance (C) of $30 \mu \mathrm{F}$ and had a charged energy of 240 or $540 \mathrm{~J}$ when a charging voltage $(\mathrm{V})$ of 4 or $6 \mathrm{kV}$, respectively, was used. The charging energy $(\mathrm{W})$ was calculated using the following equation.

$$
\mathrm{W}=1 / 2\left(\mathrm{CV}^{2}\right)
$$


Table 1. Experimental conditions for the preparation of the Sn-Bi-Ag nanoparticles.

\begin{tabular}{|c|c|c|c|}
\hline Element & $\mathrm{Sn}(\mathrm{wt} \%)$ & $\mathrm{Bi}(\mathrm{wt} \%)$ & $\mathrm{Ag}(\mathrm{wt} \%)$ \\
\hline One $0.1 \mathrm{~mm} \mathrm{Ag}$ wire, $\mathrm{N}_{2}$ gas $100 \mathrm{kPa}, 4 \mathrm{kV}$ & 31.83 & 64.20 & 3.98 \\
\hline One $0.1 \mathrm{~mm} \mathrm{Ag}$ wire, $\mathrm{N}_{2}$ gas $100 \mathrm{kPa}, 6 \mathrm{kV}$ & 39.32 & 56.27 & 4.41 \\
\hline One $0.1 \mathrm{~mm} \mathrm{Ag}$ wire, $\mathrm{N}_{2}$ gas $50 \mathrm{kPa}, 4 \mathrm{kV}$ & 35.42 & 60.56 & 4.02 \\
\hline One $0.1 \mathrm{~mm} \mathrm{Ag}$ wire, $\mathrm{N}_{2}$ gas $50 \mathrm{kPa}, 6 \mathrm{kV}$ & 39.82 & 55.55 & 4.63 \\
\hline Two $0.1 \mathrm{~mm} \mathrm{Ag}$ wire, $\mathrm{N}_{2}$ gas $50 \mathrm{kPa}, 4 \mathrm{kV}$ & 32.90 & 60.14 & 6.96 \\
\hline Two $0.1 \mathrm{~mm} \mathrm{Ag}$ wire, $\mathrm{N}_{2}$ gas $50 \mathrm{kPa}, 6 \mathrm{kV}$ & 37.72 & 54.24 & 8.04 \\
\hline
\end{tabular}

By closing a spark gap switch, the Sn-58Bi and Ag wires were heated to vaporization temperature and were turned into plasma by a pulsed high current. The particles prepared in the chamber were collected on a membrane filter by evacuating the chamber through the filter using the pump. The weight of the filter was measured in order to determine the yield of the powder.

The experimental conditions are given in Table 1 To evaporate the $\mathrm{Sn}-58 \mathrm{Bi}$ and $\mathrm{Ag}$ wires, theoretical energies $\left(\mathrm{E}_{\mathrm{v}}\right)$ of 111.12 (one $\mathrm{Sn}-58 \mathrm{Bi}$ wire $0.5 \mathrm{~mm}$ in diameter and $32 \mathrm{~mm}$ in length and one Ag wire $0.1 \mathrm{~mm}$ in diameter and $32 \mathrm{~mm}$ in length) and $119.03 \mathrm{~J}$ (one $\mathrm{Sn}-58 \mathrm{Bi}$ wire $0.5 \mathrm{~mm}$ in diameter and $32 \mathrm{~mm}$ in length and two $\mathrm{Ag}$ wires $0.1 \mathrm{~mm}$ in diameter and $32 \mathrm{~mm}$ in length) were required. The energy stored in the capacitor (Ec) was 240 or $540 \mathrm{~J}$, which was 2.16 and 4.86 (one $\mathrm{Sn}-58 \mathrm{Bi}$ wire $0.5 \mathrm{~mm}$ in diameter and $32 \mathrm{~mm}$ in length and two Ag wires $0.1 \mathrm{~mm}$ in diameter and $32 \mathrm{~mm}$ in length) and 2.02 and 4.54 (one $\mathrm{Sn}-58 \mathrm{Bi}$ wire $0.5 \mathrm{~mm}$ in diameter and
$32 \mathrm{~mm}$ in length and two $\mathrm{Ag}$ wires $0.1 \mathrm{~mm}$ in diameter and $32 \mathrm{~mm}$ in length) times $\mathrm{K} \mathrm{E} \mathrm{E}_{\mathrm{V}}$, respectively. $\mathrm{K}$ is a measure of the excess energy used for initial charging. It has been previously reported that when a $\mathrm{Cu}$ wire at $\mathrm{K}=\mathrm{E}_{\mathrm{c}} / \mathrm{E}_{\mathrm{v}}=2.0$ and $50 \mathrm{kPa}$ is used, $95 \%$ of the evaporation energy is transferred to the wire. Therefore, a value of $\mathrm{K}$ less than 2 implies a lack of explosion energy in the wire [31]. The vaporized metal gas was constrained to the inner wire by the pinch effect and inertia. When the pressure reached a critical value or became greater than the critical value, the wire momentarily inflated to form a shock wave. The metal particles and gas were ejected quickly, and fine particles could be formed.

The phase and the shape associated with synthesis were characterized by X-ray diffraction (XRD, Rigaku RINT $2500 \mathrm{HF}$ with $\mathrm{Cu} \mathrm{K \alpha}$ radiation) and field emission scanning electron microscopy (FE-SEM; Zeiss SUPRA25). The results of the XRD analysis were assigned to the Scherrer equation
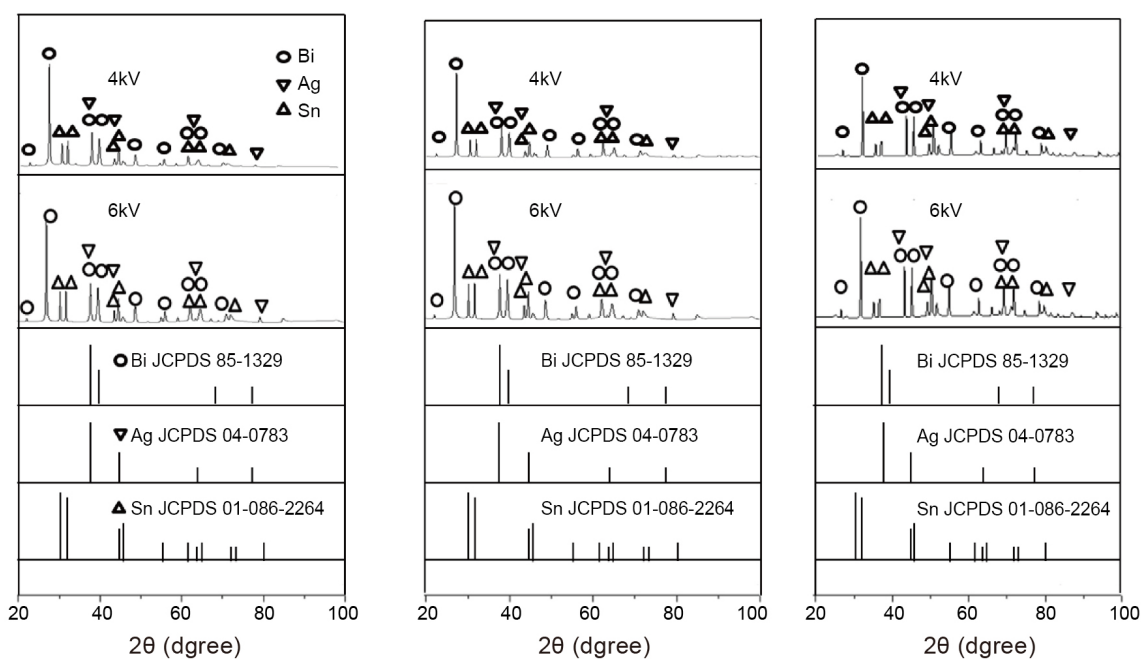

Fig. 3. XRD patterns of the particles synthesized by using 42Sn-58Bi and $\mathrm{Ag}$ wires under the following conditions: (a) One $0.1 \mathrm{~mm} \mathrm{Ag}$ wire and $\mathrm{N}_{2}$ gas at $100 \mathrm{kPa}$, (b) One $0.1 \mathrm{~mm} \mathrm{Ag}$ wire and $\mathrm{N}_{2}$ gas at $50 \mathrm{kPa}$ and (c) Two $0.1 \mathrm{~mm} \mathrm{Ag}$ wires and $\mathrm{N}_{2}$ gas at $50 \mathrm{kPa}$. 
Table 2. Results at $27.2^{\circ}$ calculated from the Scherrer equation for each condition.

\begin{tabular}{cccc} 
& (a) One $0.1 \mathrm{~mm} \mathrm{Ag}$ wire, $\mathrm{N}_{2}$ gas $100 \mathrm{kPa}$ & (b) One $0.1 \mathrm{~mm} \mathrm{Ag}$ wire, $\mathrm{N}_{2}$ gas 50kPa & (c) Two 0.1 mm Ag wire, $\mathrm{N}_{2}$ gas 50kPa \\
\hline \multirow{2}{*}{$4 \mathrm{kV}$} & $\beta=0.64^{\circ}$ & $\beta=1.02^{\circ}$ & $\beta=0.86^{\circ}$ \\
& $\tau=45.31 \mathrm{~nm}$ & $\tau=28.43 \mathrm{~nm}$ & $\tau=34.11 \mathrm{~nm}$ \\
\hline \multirow{2}{*}{$6 \mathrm{kV}$} & $\beta=1.16^{\circ}$ & $\beta=1.66^{\circ}$ & $\beta=1.24^{\circ}$ \\
& $\tau=25 \mathrm{~nm}$ & $\tau=16 \mathrm{~nm}$ & $\tau=23.57 \mathrm{~nm}$ \\
\hline
\end{tabular}

and the particle size was analyzed. The Scherrer equation is shown in equation (2) below. $\tau$ is the mean size of the ordered domains, which may be smaller or equal to the grain size, $\mathrm{K}$ is a dimensionless shape factor (with a typical value of about $0.9), \lambda$ is the $\mathrm{X}$-ray wavelength $(\mathrm{Cu} \mathrm{K \alpha}, 1.5406 \AA), \beta$ is the line broadening at half the maximum intensity(FWHM, 2 $\theta), \theta$ is the Bragg angle.

$$
\tau=\mathrm{K} \lambda / \beta \cos \theta
$$

For particle size distribution, 30 images were taken using FE-SEM, and particle sizes were measured for each particle. Then, after counting particles at $0.5 \mathrm{~nm}$ intervals, the values were entered and the OriginPro 8 Program was used to show the results in the form of a bar graph. Then the results of the Scherrer equation and the particle size distribution by FE-SEM are compared.

Finally, a differential scanning calorimeter (DSC 8000, PerkinElmer) was used to monitor the changes in the melting point.

\section{RESULTS AND DISCUSSION}

Figure 3 shows the XRD patterns of the synthesized powders. Each XRD pattern shows the same peaks. This indicates that the crystallized particles, which consisted of $\mathrm{Sn}-\mathrm{Bi}-\mathrm{Ag}$, were of a single phase. Sn-Bi-Ag was formed successfully because the $K$ factor was $\geq 2$. Table 2 shows the results of particle size calculation using the Scherrer equation under each condition. The particle size was calculated at $27.2^{\circ}$, which is the peak of $\mathrm{Bi}$ with the highest peak intensity. It can be seen from this result that as the applied charging voltage increases, or as the gas pressure decreases, the particle size decreases. Table 3 shows the SEM- Energy Dispersive Spectrometry (EDS) results of the particles under different experimental conditions.

When one $\mathrm{Sn}-58 \mathrm{Bi}$ wire $(0.5 \mathrm{~mm}$ in diameter and $32 \mathrm{~mm}$ in length) and one $\mathrm{Ag}$ wire $(0.1 \mathrm{~mm}$ in diameter and $32 \mathrm{~mm}$ in length) were used, the theoretical composition of the wires was: $\mathrm{Sn}=40.08, \mathrm{Bi}=55.34$, and $\mathrm{Ag}=4.58 \mathrm{wt} \%$. On the other hand, when one $\mathrm{Sn}-58 \mathrm{Bi}$ wire $(0.5 \mathrm{~mm}$ in diameter and $32 \mathrm{~mm}$ in length) and two $\mathrm{Ag}$ wires $(0.1 \mathrm{~mm}$ in diameter and $32 \mathrm{~mm}$ in length) were used, the theoretical composition of the wires was: $\mathrm{Sn}=38.32, \mathrm{Bi}=52.92$, and $\mathrm{Ag}=8.76 \mathrm{wt} \%$. The theoretical and experimental compositions differed when a charging voltage of $4 \mathrm{kV}$ was applied. On the other hand, at $6 \mathrm{kV}$, it was found that the composition of the target was close to that of the wires because the energy was well-supplied to the wires. Thus, we can state that a necessary condition for obtaining alloy nanopowders with a difference in sublimation energy is to supply a high energy to the wires, which also reduces the pressure. We then investigated the use of the PWD method for subjecting wires with limited solid solubility to extreme energies to produce nanopowders.

Figure 4 shows the FE-SEM microstructural images of the

Table 3. EDS analysis of the $\mathrm{Sn}-\mathrm{Bi}-\mathrm{Ag}$ nanoparticles formed using the PWD method.

\begin{tabular}{c|c|c}
\hline Metal Wire & $\begin{array}{c}\text { One } \mathrm{Sn}-\mathrm{Bi}: \\
\begin{array}{c}0.5 \times 32 \mathrm{~mm} \\
\text { One Ag: } \\
\phi 0.1 \times 32 \mathrm{~mm}\end{array}\end{array}$ & $\begin{array}{c}\text { One Sn-Bi: } \\
\phi 0.5 \times 32 \mathrm{~mm} \\
\text { Two Ag: } \\
\phi 0.1 \times 32 \mathrm{~mm}\end{array}$ \\
\hline $\begin{array}{c}\text { Vaporization energy of the wire } \\
\left(\mathrm{E}_{\mathrm{V}} / \mathrm{J}\right)\end{array}$ & 111.12 & 119.03 \\
\hline $\begin{array}{c}\text { Capacitance of capacitor } \\
(\mathrm{C} / \mu \mathrm{F})\end{array}$ & 30 & 30 \\
\hline $\begin{array}{c}\text { Charging Voltage } \\
\left(\mathrm{V}_{\mathrm{C}} / \mathrm{kV}\right)\end{array}$ & 4,6 & 4,6 \\
\hline $\begin{array}{c}\text { Charging energy } \\
\left(\mathrm{E}_{\mathrm{C}} / \mathrm{J}\right)\end{array}$ & 240,540 & 240,540 \\
\hline $\begin{array}{c}\text { Relative energy } \\
\left(\mathrm{K}=\mathrm{E}_{\mathrm{C}} / \mathrm{E}_{\mathrm{V}}\right)\end{array}$ & $2.16,4.86$ & $2.02,4.54$ \\
\hline $\begin{array}{c}\text { Pressure of atmosphere gas } \\
(\mathrm{Pa} / \mathrm{kPa})\end{array}$ & $\begin{array}{c}50,100 \\
\left(\mathrm{~N}_{2} \text { gas }\right)\end{array}$ & $\begin{array}{c}50 \\
\left(\mathrm{~N}_{2} \text { gas }\right)\end{array}$ \\
\hline
\end{tabular}




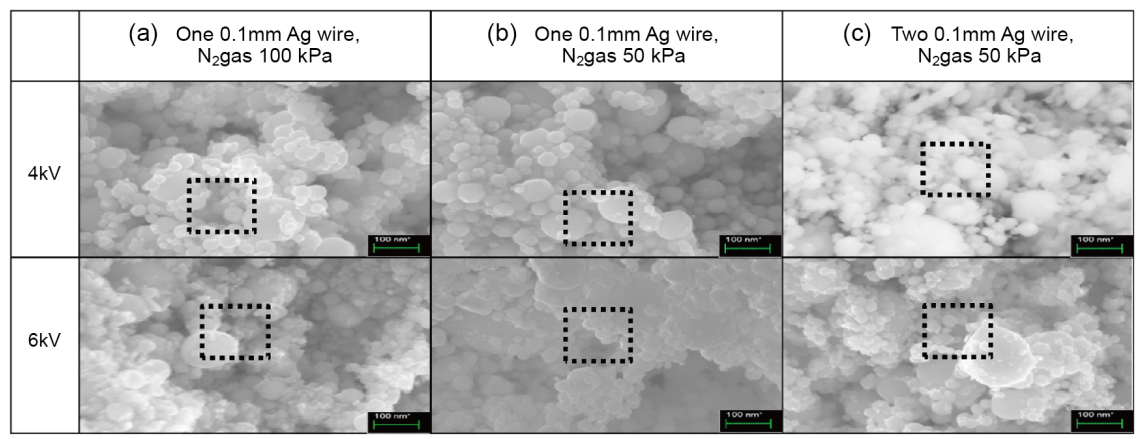

Fig. 4. FE-SEM images of the particles synthesized by using 42Sn-58Bi and Ag wires under the following conditions : (a) One $0.1 \mathrm{~mm}$ $\mathrm{Ag}$ wire and $\mathrm{N}_{2}$ gas at $100 \mathrm{kPa}$, (b) One $0.1 \mathrm{~mm} \mathrm{Ag}$ wire and $\mathrm{N}_{2}$ gas at $50 \mathrm{kPa}$ and (c) Two $0.1 \mathrm{~mm} \mathrm{Ag}$ wire and $\mathrm{N}_{2}$ gas at $50 \mathrm{kPa}$

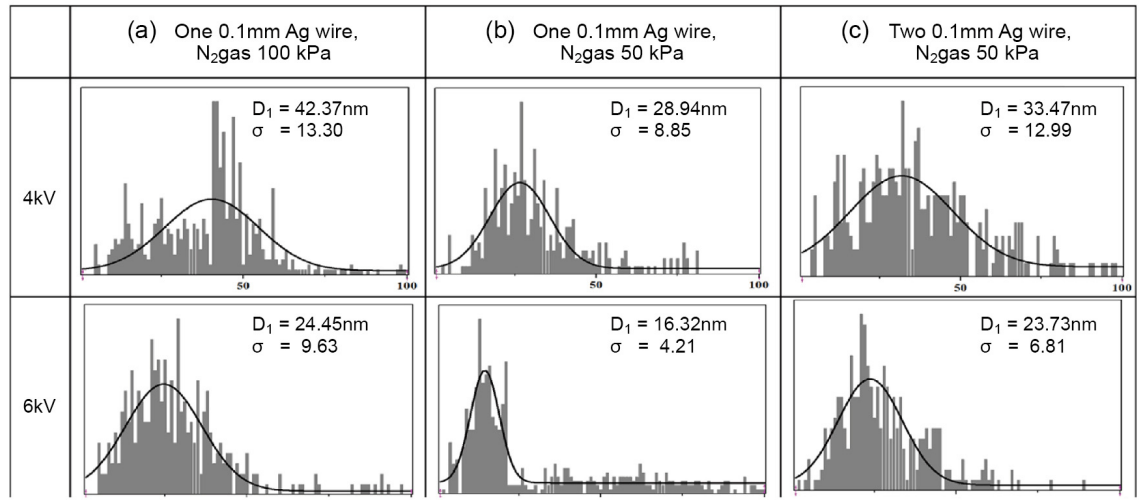

Fig. 5. Particles size distribution obtained by analyzing the FE-SEM image of the particles with diameters in the range of $0-100 \mathrm{~nm}$.

particles synthesized under various conditions. These images reveal that spherical particles were formed with diameters in the range of $16.32-42.37 \mathrm{~nm}$. This confirms that nano-sized particles were synthesized by the PWD method. The particle size distribution is shown in Fig. 5. The curves shown in Fig. 5 represent the log-normal distribution curves fitted to the experimental results. The shape of the $\mathrm{Sn}-58 \mathrm{Bi}$ and $\mathrm{Ag}$ nanoparticles was spherical. The particle-size distributions show that the mean particle diameter (D1) of the Sn-Bi and $\mathrm{Ag}$ nanopowders was within the range of 16.32-42.37 $\mathrm{nm}$ for each experimental condition. A large $\mathrm{K}$ factor implies that the energy supplied to the wires was large. The $\mathrm{K}$ factor is defined as $E_{C} / E_{V}$. $E_{C}$ was calculated from Eqn. (1). It was found that the most important factor for determining the particle size was the voltage. The application of a high voltage to the wires led to the formation of fine particles. Based on the results shown in Fig. 4, 5 and Table 3, we can conclude that the higher the voltage applied to the wires, the smaller the size of the particles and the higher the Ag content. In addition, an increase in the number of $\mathrm{Ag}$ wires resulted in an increase in the particle size and $\mathrm{Ag}$ content. Further, comparing the particle size results in Fig. 5 and Table 2, it can be concluded that the same result was obtained because all the errors are smaller than $3 \mathrm{~nm}$. The reason for the error is that the results in Table 2 were only measured for the primary peaks of $\mathrm{Bi}$, while the results in Fig. 5 were based on averaging of the particle size distribution results. Nonetheless, this result shows that most of the particles had a particle size consistent with the primary peak of $\mathrm{Bi}$, and the number increased as the applied charging voltage increased, or as the pressure decreased. This result is the same as the previous result.

The collection rates under different conditions are shown in Fig. 6. The plots reveal that the collection rate increased linearly with an increase in voltage up to $\sim 6 \mathrm{kV}$ and was saturated at $99.148 \%$. This result indicates that the collection 


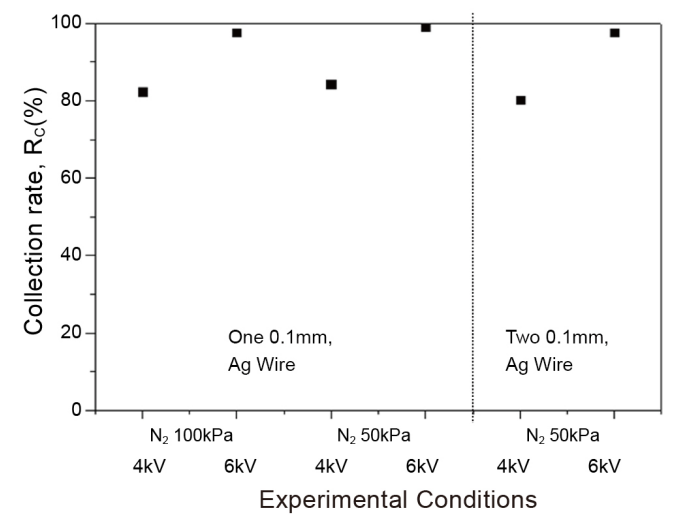

Fig. 6. Collection rate of the particles as a function of voltage under different experimental conditions

rate depends on the voltage level in the wires regardless of the pressure of $\mathrm{N}_{2}$ gas $(50$ or $100 \mathrm{kPa}$ ). These results are reasonable because the wires may not be sufficiently vaporized to form nanoparticles at low voltages. This is in good agreement with the EDS results, which revealed that the $\mathrm{Ag}$ content was low at $4 \mathrm{kV}$. However, at $6 \mathrm{kV}, \mathrm{Ag}$ nanoparticles were formed, as observed from the EDS (Table 3) and XRD (Fig. 3) results. The results reveal that nanoparticles were successfully formed at $6 \mathrm{kV}$. Figure 7 shows the thermal profile of the Sn-Bi-Ag alloy nanoparticles. The melting point of the $\mathrm{Sn}-\mathrm{Bi}-\mathrm{Ag}$ nanoparticles was found to be within the range of 188.68 $214.97{ }^{\circ} \mathrm{C}$, which is about $40{ }^{\circ} \mathrm{C}$ lower than that obtained from the phase diagram and computational thermodynamics of the Sn-Bi-Ag system. A size-dependent reduction in the melting point was confirmed.

\section{CONCLUSIONS}

We successfully synthesized three-component nanoparticles of Sn-58Bi and Ag by PWD using Sn-58Bi and Ag wires. We also investigated the effect of voltage and gas pressure on the particle size and composition of the synthesized alloy nanoparticles. Alloy nanopowders of $\mathrm{Sn}-58 \mathrm{Bi}$ and $\mathrm{Ag}$ were obtained at voltages greater than $4 \mathrm{kV}$ in $\mathrm{N}_{2}$ atmosphere using Ag wires with a diameter of $0.1 \mathrm{~mm}$. Under these conditions, the charging energy of the capacitor was higher than the sublimation energy of the $\mathrm{Sn}-58 \mathrm{Bi}$ and $\mathrm{Ag}$ wires. In this

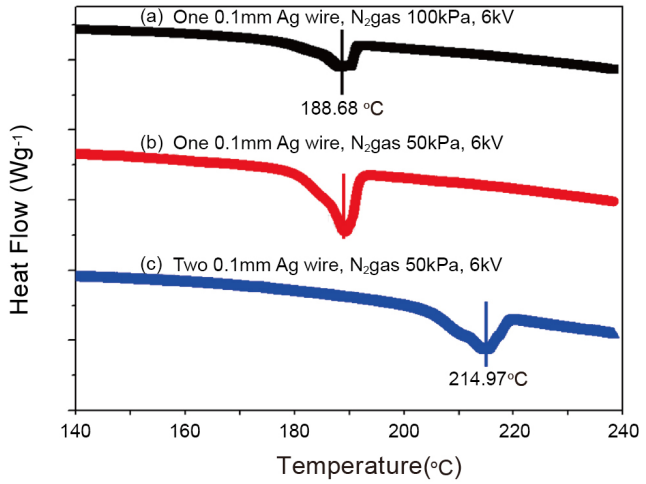

Fig. 7. DSC curves of the particles synthesized by using 42Sn-58Bi and $\mathrm{Ag}$ wires under the following conditions: (a) One $0.1 \mathrm{~mm} \mathrm{Ag}$ wire, $\mathrm{N}_{2}$ gas at $100 \mathrm{kPa}$, and $6 \mathrm{kV}$, (b) $0.1 \mathrm{~mm} \mathrm{Ag}$ wire, $\mathrm{N}_{2}$ gas at $50 \mathrm{kPa}$, and $6 \mathrm{kV}$ and (c) Two $0.1 \mathrm{~mm} \mathrm{Ag}$ wires, $\mathrm{N}_{2}$ gas at $50 \mathrm{kPa}$, and $6 \mathrm{kV}$.

study, we supplied extreme energies to the $\mathrm{Sn}-58 \mathrm{Bi}$ and $\mathrm{Ag}$ wires by the PWD method to overcome the limited solid solubility of these wires, in order to form nanopowders. For successful synthesis of the three-component alloy nanoparticles, a high voltage and low gas pressure were required. The results reveal that when a voltage of $6 \mathrm{kV}$ was used, the composition of the particles was constant and their size could be controlled. It was also confirmed that a reduction in particle size resulted in a reduction in the melting point of the resulting nanopowders. Through the results of this study, we can confirm the conditions for reducing the size of nanopowders, and think that it is possible to utilize the Sn-Bi-Ag based solder material at a lower temperature by controlling these conditions. The results indicate that Sn-Bi-Ag based solder, which is a material harmless to the human body, can be utilized as a solder material.

\section{ACKNOELEDGEMENTS}

This research was supported by the Ministry of Trade, Industry \& Energy(MOTIE), Korea Institute for Advancement of Technology(KIAT) and Ulsan Institute For Regional Program Evaluation(IRPE) through the Encouragement Program for The Industries of Economic Cooperation Region. 


\section{REFERENCES}

1. Z. Mei, and J. W. Moris, J. Electron. Mater. 21, 599 (1992).

2. Z. Moser, W. Gasior, and J. Pstrus, J. Electron. Mater. 30, 1104 (2001).

3. K. Suganuma, Curr. Opin. Solid St. M. 5, 55 (2001).

4. K. Suganuma, T. Sakai, K .S. Kim, Y. Takagi, J. Sugimoto, and M. Ueshima, IEEE T. Comp. Pack. Man. 25, 257 (2002).

5. R.K. Shiue, L. W. Tsay, C. L. Lin, and J. L. Ou, J. Mater. Sci. 38, 1269 (2003).

6. J. W. Morris Jr, J. L. F. Goldstein, and Z. Mei, JOM 45, 25 (1993).

7. H. Sun, Q. Li, and Y. C. Chan, and J. Mater. Sci. Mater. El. 25, 4380 (2014).

8. H. J. Jiang, K. S. Moon, F. Hua, and C. P. Wong, Chem. Mater. 19, 4482 (2007).

9. M. Wautelet, Nanotechnology 3, 42 (1992).

10. Y. H. Jo, I. Y. Jung, C. S. Choi, I. Y. Kim, and H. M. Lee, Nanotechnology 22, 225701 (2011).

11. A. D. Zdetsis, Nanoscale Res. lett. 6, 1 (2011).

12. K. S. Jang, Y. S. Eom, J. T. Moon, Y. S. Oh, and J. D. Nam, J. Nanosci. Nanotechno. 9, 7461 (2009).

13. G. Ouyang, G. Yang, and G. Zhou, Nanoscale 4, 2748 (2012).

14. M. Ghasemi, Z. Zanolli, M. Stankovski, and J. Johansseon, Nanoscale 7,17387(2015).

15. A. Roshanghias, A. Yakymovych, J. Bernardi, and H. Ipser, Nanoscale 7, 5843 (2015).

16. S. L. Lai, J. Y. Guo, V. Petrova, G. Ramanath, and L. H. Allen, Phys. Rev. Lett. 77, 99 (1996).

17. Y. C. Ha, C. H. Cho, Y. U. Kim, and H. J. Sohn, J. Korean Phys. Soc. 59, 3458 (2011).
18. J. Shen, Y. C. Chan, Microelectron. Reliab. 49, 223 (2009).

19. T. K. Sindhu, R. Sarathi, and S. R. Chakravarthy, Nanotechnology 19, 025703 (2007).

20. F. G. Karioris, B. R. Fish, J. Colloid Interf. Sci. 17, 155 (1962).

21. J. H. Kim, D. S. Kim, H. Suematsu, and K. Tanaka, Korean J. Met. Mater. 22, 23 (2017).

22. W. Jiang and K. Yatsui, IEEE T. Plasma Sci. 26, 1498 (1998).

23. H. Suematsu, S. Nishimura. K. Murai, Y. Hayashi, T. Suzuki, T. Nakayama, W. Jiang, A. Yamazaki, K. Seki, and K. Niihara, Rev. Sci. Instrum. 78, 056105 (2007).

24. Y. Tokoi, T. Suzuki, T. Nakayama, H. Suematsu, F. Kaneko, and K. Niihara, Scripta Mater. 63, 937 (2010).

25. E. Tronc, D. Fiorani, M. Noguès, A. M. Testa, F. Lucari, F. D. Orazio, J. M. Grenèche, W. Wernsdorfer, N. Galvez, C. Chanèac, D. Mailly, and J. P. Jolivet, J. Magn. Mater. 262, 6 (2003).

26. C. H. Cho, Y. Kinemuchi, H. Suematsu, W. Jiang, and K. Yatsui, JPN J. Appl. Phys. 42, 1763 (2003).

27. E. M. Abdelkader, P. A. Jelliss, and S. W. Buckner, Inorg. Chem. 54, 5897 (2015).

28. S. Ishihara, T. Koishi, T. Orikawa, H. Suematsu, T. Nakayama, T. Suzuki, and K. Nihara, Intermetallics 23, 134 (2012).

29. K. Suwa, T. Nakayama, T. Suzuki, H. suematsu, W. Jiang, and K. Niihara, JPN J. Appl. Phys. 47, 775 (2008).

30. D. S. Kim, J. H. Kim, H. Suematsu, K. Tanaka, and B. K. Ryu, Met. Mater. Int. 22, 319 (2016).

31. K. Murai, C. H. Cho, H. Suematsu, W. Jiang, and K. Yatsui, IEEJ Trans. Fundam. Mater. 125, 39 (2005).

32. K. Suganuma, S. H. Huh, K. S. Kim, H. Nakase, and Y. Nakamura, Mater.Trans. 42, 286 (2001). 